This document is the accepted manuscript version of the following article:

Honorio, T., Chemgne Tamouya, O. M., \& Shi, Z. (2020). Specific ion effects control the thermoelastic behavior of nanolayered materials: the case of crystalline alkali-silica reaction products. Physical Chemistry Chemical Physics, $22(47)$, 27800-27810. https://doi.org/10.1039/D0CP04955G

\title{
Specific ion effects control the thermoelastic behavior of alkali-silica reaction products
}

\author{
Tulio Honorio ${ }^{\mathrm{a}, *}$, Ornella M. Chemgne Tamouya ${ }^{\mathrm{a}}$, Zhenguo Shi ${ }^{\mathrm{b}}$ \\ ${ }^{a}$ Université Paris-Saclay, ENS Paris-Saclay, CNRS, LMT - Laboratoire de Mécanique et \\ Technologie, 91190, Gif-sur-Yvette, France \\ ${ }^{b}$ Laboratory for Concrete \& Construction Chemistry, Swiss Federal Laboratories for \\ Materials Science and Technology (Empa), 8600 Dübendorf, Switzerland
}

\begin{abstract}
We perform molecular simulations to characterize the structure and the thermo-mechanical behavior of crystalline alkali-silica reaction (ASR) products, whose structure is analogous to shlykovite's, a layered silicate. As chargebalancing cations, we study $\mathrm{Na}$ and $\mathrm{K}$ (the most relevant alkali involved in ASR) as well as Li and Cs. For the first time, the thermal and elastic properties of shlykovite are computed using molecular simulations. The simulations reveal that the charge-balancing cations control thermo-elastic properties of shlykovite, following the example of other phyllosilicates. Change balance ion affects the number of H-bonds in the order $\mathrm{Cs}>\mathrm{K}>\mathrm{Na}>\mathrm{Li}$, and that observation can be associated with the variations in the computed thermo-mechanical properties. Using as input the elastic properties obtained from the molecular scale and assuming long-range disorder at the mesoscale (through a simplified representation of the gel scale), we provide mean-field homogenization estimates of the elastic constants at the gel scale that are consistent with indentation data. This result suggests a nanogranular texture of ASR gels.

Keywords: Elasticity; Thermal properties; Shlykovite; H-bonds;

Phyllosilicates.
\end{abstract}

\footnotetext{
${ }^{*}$ Corresponding author

Email address: tulio.honorio-de-faria@ens-paris-saclay.fr (Tulio Honorio)
} 


\section{Introduction}

Phyllosilicates are encountered in geomaterials including clays, asbestos, and man-made geomaterials such as concrete. The interlayer (micro-)pore in phyllosilicates is generally filled by water and charge balance ions. Research on 5 clays shows that these charge-balance ions are critical in the hygro-mechanical response of phyllosilicates affecting decisively the volume stability and hysteresis in swelling clays 1 , 2, 3. The influence of charge-balance ions on elastic properties, thermal expansion, and heat capacity of phyllosilicates is less studied, though. In this context, molecular simulations revealed significant differences in the elastic constants and thermal expansion of $\mathrm{Na}$ - and $\mathrm{Ca}$-montmorillonite 2. The effects of other charge balancing cations are still to be quantified, notably in other industrial relevant layered minerals, such as the ones found in concrete (e.g. calcium and magnesium silicates, AFm phases).

Concrete is the most produced materials on the world being responsible for ${ }_{15} 5-8 \%$ of anthropogenic $\mathrm{CO}_{2}$ emissions [4. Extending the service life of existing concrete structure and engineering cement-based material to better durability is crucial to reduce the negative impacts of using concrete. Alkali-silica reaction (ASR) is one of the main durability problems affecting critical infrastructure (e.g. for energy production, transportation systems, sanitation, and water supply) made of concrete. This problem results from the reaction between the alkaline pore solution of cement-based materials and the poorly crystalline silica encountered in aggregates (e.g. [5, 6]) resulting in a product that leads to expansion of concrete. Formation of ASR products is associated with cracking leading to a reduction in the mechanical properties and, consequently reducing

25 the service life of the affected structures [7. Fundamental questions remain open regarding the physical origin of the expansive behavior, the structure, and the properties of the ASR products. We still know relatively little about the physical origins of the fundamental physical properties of ASR products, despite their importance in the understanding of the mechanism associated with

30 ASR damage. Such damage is known to be affected by hygrothermal conditions 
and applied stress [8, 9]. Assessing the thermo-mechanical properties of ASR products at the nanoscale may bring new physical insights to the comprehension of ASR damage. This knowledge can be applied to predict and control ASR, propose new therapies to treat this construction pathology and extend the range 35 of local aggregates alternatives for concrete mix design reducing the impact of using concrete.

Experimental characterization of ASR products is challenging since these products occur in small amounts, generally coexisting with other silica-rich phases encountered in cement-based materials [7]. Additionally, at the mesoscale

40 ASR products often present small crystallites and long-range disorder which make difficult its experimental assessment [10. In this context, molecular modeling arises as a powerful tool to unveil the physical origins and provide atomiclevel information about ASR products. Molecular-scale simulations enable evaluating nanoscale systems under well-controlled conditions and without the dif-

45 ficulties related to the disorder, and composition variability of the various complex phases encountered in cement-based materials. To date, only a few studies have coped with the molecular modeling of ASR products. Kirkpatrick et al. [1] performed molecular dynamics (MD) simulations using kanemite structure to represent nano-crystalline ASR. However, recent studies show that kanemite molecular structure is not equivalent to the structure of ASR gels found in concrete [12, 13. A recent experimental study [12] shows that ASR products are similar to the naturally occurring mineral shlykovite $\left.\left(\mathrm{KCa}\left[\mathrm{Si}_{4} \mathrm{O}_{9}(\mathrm{OH})\right] \cdot 3 \mathrm{H}_{2} \mathrm{O}\right]\right)$ [14, with isomorphic substitutions of potassium by sodium taking place according to the composition of the pore solution.

In this work, we carry out classical MD simulations to understand, with atomic-level detail, the physical origins of the thermo-mechanical response of shlykovite. This is the first time that the thermo-mechanical properties of shlykovite are computed using molecular simulations. We consider shlykovite with either Li, Na-, K- or Cs- substitutions. Sodium and potassium are one of 60 the main alkali found in cement-based materials pore solutions [15, 16. Lithium substitutions are not generally observed in ASR products; lithium salts are, 
though, often deployed to mitigate ASR [17. The analysis of Li-shlykovite can, therefore, provide insights on ASR prevention and therapy. Cesium can be incorporated in ASR products altering the mesotexture [18, these effects are relevant for concrete structures for nuclear energy production and waste disposal [18]. We assess the effects of the charge balancing ion on the thermal expansion, heat capacity, and elastic constants of shlykovite. To unveil the details of the nanoscale origin of the thermo-mechanical properties of crystalline ASR products we look at the changes in water structure and hydrogen bond network induced by the presence of the different charge balance cations.

\section{Molecular models and methods}

The atomic structure of shlykovite (monoclinic, space group $\mathrm{P} 2_{1} / \mathrm{c}$ ) as reported by Zubkova et al. 14 is used. Figure 1 shows a snapshot of Na-shlykovite (i.e. a structure in which all $\mathrm{K}$ atoms are substituted by Na atoms), which is 75 representative of the structure with $\mathrm{K}, \mathrm{Li}$, and $\mathrm{Cs}$ as charge balance cations. Shlykovite exhibits intra-layer (sandwiched in-between silicate sheet at the same plan level as intra-layer calcium within a layer) and inter-layer water.

We use a reparametrization [19] of ClayFF [20] with SPC/E water 21] to model the interaction in shlykovite. This reparametrization has been recently used by us to compute the effective interaction and study the stability of $\mathrm{Na}$ ) and K-shlykovite under sorption [19. The parameters describing interactions with $\mathrm{K}$ and $\mathrm{Na}$ are taken from the respective aqueous ions in ClayFF. The parameters for Cs are taken from ref. 222 and for and Li, from ref. [23].

Simulation are performed with LAMMPS package 24]. Periodic boundary conditions are adopted. Long-range electrostatic interactions are accounted for using Ewald summation methods with precision in terms of forces of $10^{-5}$. Tail corrections are used to cope with long-range van der Waals interactions.

The $\sigma \mathrm{T}$ simulations were performed with Nosé-Hoover thermostat and barostat with damping parameters of 100 and 1000 timesteps, respectively. Elastic constants were obtained by a finite difference approach in which the simula- 

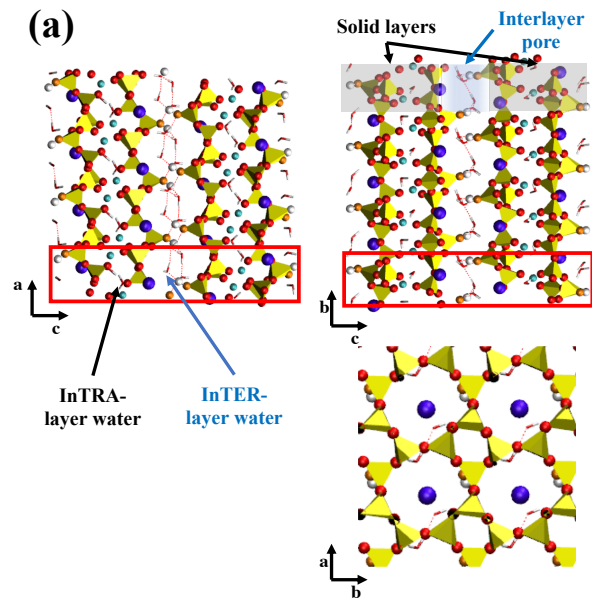

\begin{tabular}{|ll|}
\hline 0 & $\mathrm{Na}$ \\
0 & $\mathrm{Ca}$ \\
0 & $\mathrm{O}$ \\
0 & $\mathrm{O}_{\mathrm{H}}$ \\
$\cup$ & $\mathrm{H}$ \\
$\downarrow$ & $\mathrm{H}_{2} \mathrm{O}$ \\
$\triangle$ & $\mathrm{Si}$ \\
\hline
\end{tabular}

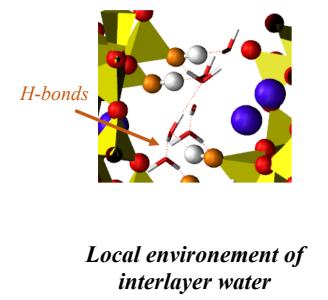

(b)

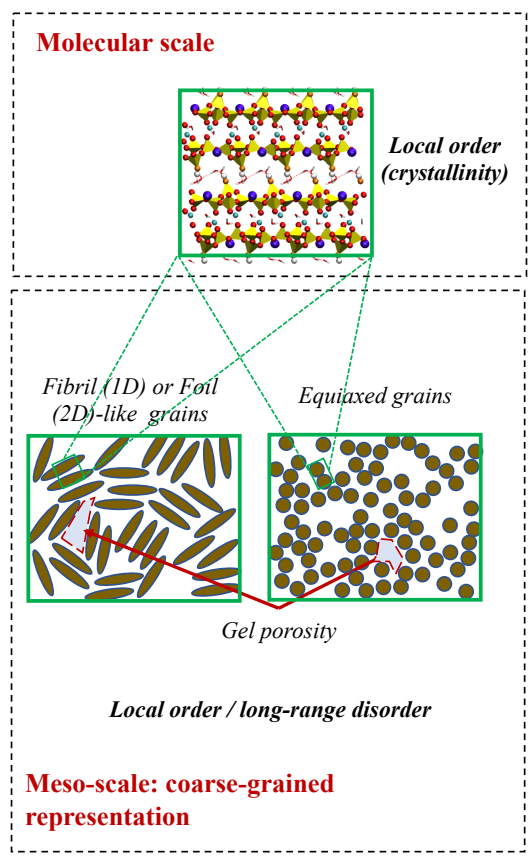

Figure 1: (a) Snapshot of X-shlykovite (with charge balance cation $\mathrm{X}=\mathrm{Li}, \mathrm{Na}, \mathrm{K}$, or Cs) for a number of water molecules $n=3$ (per $\mathrm{Ca}\left[\mathrm{Si}_{4} \mathrm{O}_{9}(\mathrm{OH})\right]$ ), equilibrated at $296 \mathrm{~K}$ and under $1 \mathrm{~atm}$. View on $a c, b c$ and $a b$ plans and local environment within the interlayer with H-bonds depicted. pore along $b$ (top, left) and $a$ (top, right) axis. (b) Sketches of a possible representation of the multiscale microstructure of ASR products: (local) order at the molecular scale (shlykovitelike) and disorder at the mesoscale where grains (portions of the materials that can be fibril-like foil-like or equiaxed). The (additional) gel porosity resulting from disorder is depicted. 
tion supercell (obtained from the replication of the unit cell twice in $a$ - and $b$-directions) were slightly deformed in each one of the six axial and tangential directions followed by minimization.

\section{Results and discussion} in calcium silicate hydrates [25]).

Table 1 gathers the results of the lattice parameters, volume, and density obtained in an $\mathrm{N} \sigma \mathrm{T}$ simulation at $296 \mathrm{~K}$ and under $1 \mathrm{~atm}$. The $\mathrm{N} \sigma \mathrm{T}$ results are 

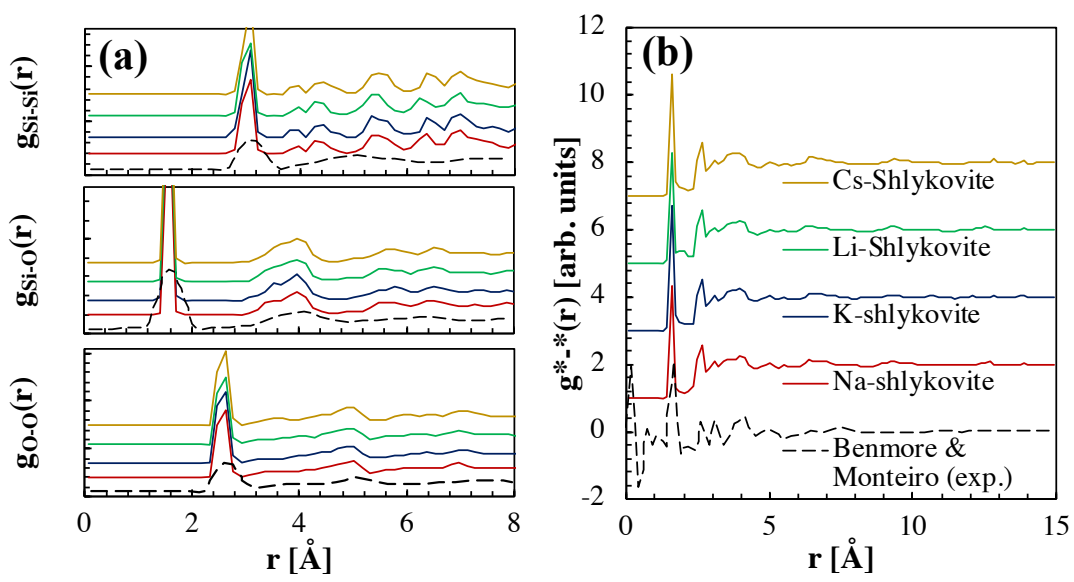

Figure 2: Radial distribution functions (RDF) $g_{i-j}(r)$ of (a) pairs $i$ and $j$ and (d) total pair distribution functions $g_{*-*}(r)$ obtained from molecular simulations on $\mathrm{Li}, \mathrm{Na}-, \mathrm{K}-$ and Csshlykovite at $300 \mathrm{~K}$ and under $1 \mathrm{~atm}$ compared to the experimental results of Benmore and Monteiro [10] on ASR gels. The curves were shifted to improve the readability.

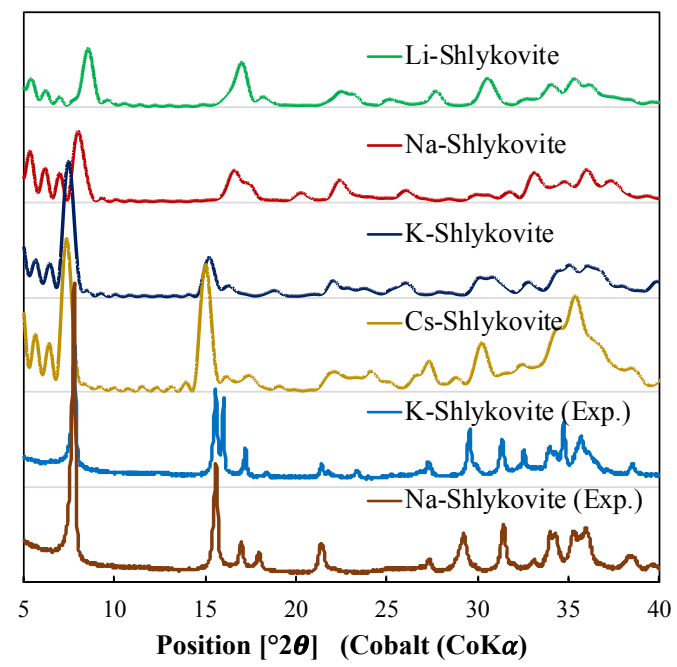

Figure 3: XRD pattern of Li-, Na-, K- and Cs-shlykovite computed with the configurations from MD simulations (using Debyer code (https://debyer.readthedocs.io)) at $296 \mathrm{~K}$ and under $1 \mathrm{~atm}$ compared to the experimental pattern reported by Shi et al. [12] for Na- and Kshlykovite. The curves were shifted to improve the readability. 
Table 1: Lattice parameters, volume $V$ and density $\rho$ of $\mathrm{K}-$, Na-, Li- and Cs-shlykovite obtained from $\mathrm{N} \sigma \mathrm{T}$ simulations at $296 \mathrm{~K}$ and 1 atm: comparison against experimental data from data from Zubkova et al. 14 for (K-)shlykovite.

\begin{tabular}{c|c|cccc}
\hline & (K-)Shlykovite & Li-Shlykovite & Na-Shlykovite & K-Shlykovite & Cs-Shlykovite \\
& Zubkova et al. 14 & $\mathrm{~N} \sigma \mathrm{T}$ & $\mathrm{N} \sigma \mathrm{T}$ & $\mathrm{N} \sigma \mathrm{T}$ & $\mathrm{N} \sigma \mathrm{T}$ \\
\hline$a[\AA]$ & 6.4897 & $6.33 \pm 0.04$ & $6.35 \pm 0.05$ & $6.40 \pm 0.04$ & $6.43 \pm 0.04$ \\
$b[\AA]$ & 6.6669 & $6.93 \pm 0.04$ & $6.92 \pm 0.04$ & $6.90 \pm 0.04$ & $6.92 \pm 0.04$ \\
$c[\AA]$ & 26.714 & $24.78 \pm 0.70$ & $24.89 \pm 0.61$ & $27.29 \pm 0.30$ & $27.36 \pm 0.57$ \\
$\alpha\left[^{\circ}\right]$ & 90 & $88.5 \pm 4.8$ & $90.0 \pm 3.8$ & $90.0 \pm 2.4$ & $89.7 \pm 3.7$ \\
$\beta\left[^{\circ}\right]$ & 94.697 & $90.1 \pm 4.3$ & $89.9 \pm 3.6$ & $91.6 \pm 5.6$ & $91.6 \pm 4.3$ \\
$\gamma\left[{ }^{\circ}\right]$ & 90 & $88.4 \pm 0.9$ & $90.0 \pm 1.0$ & $90.0 \pm 0.7$ & $90.0 \pm 0.6$ \\
\hline$V\left[\AA^{3}\right]$ & 1209.12 & $1079 \pm 28$ & $1089 \pm 25$ & $1200 \pm 14$ & $1211 \pm 25$ \\
$\rho\left[\mathrm{g} / \mathrm{cm}^{3}\right]$ & 2.244 & $2.31 \pm 0.06$ & $2.38 \pm 0.05$ & $2.25 \pm 0.03$ & $2.75 \pm 0.06$ \\
\hline
\end{tabular}

consistent with the experimental data provided by Zubkova et al. 14, referring to the K-shlykovite. The volume, $a$ and $c$ lattice parameter follows the sequence of cation size $(\mathrm{Li}<\mathrm{Na}<\mathrm{K}<\mathrm{Cs}$ ), whereas $b$ remains approximately constant.

\subsection{Thermo-mechanical properties under undrained conditons}

We compute the heat capacity, the anisotropic tensor of thermal expansion and the elastic constants, which are the main properties governing the thermomechanics, of Li-, K-, Na- and Cs-Shlykovite. We adopt the hydration state with $n=3$, which is associated with the naturally occurring (K-)shlykovite [14] and the laboratory synthesized $\mathrm{K}$ and Na-shlykovite [26, 27, 12. The response of a microporous geomaterial at constant hydration state can be related to the

${ }_{130}$ "undrained" (or "close pore") condition in poromechanics in contrast with the "drained" (or "open pore") condition (e.g [28, 29]). Undrained conditions may be associated with the instantaneous response of the materials (i.e. the fluids in the micropore do not have enough time to exchange with the neighboring pore so they contribute to the thermomechanical response), while drained conditions with longer timescales (i.e. enough time is left to the fluid to be in equilibrium with the neighboring larger pores according to the thermomechanical solicitation) [30. The elastic response is an example of property often associated with instantaneous response in geomaterials, in opposition to the viscoelastic (or delayed) response observed in clayey and cement-based materials that can be linked to the water exchange 31 . 

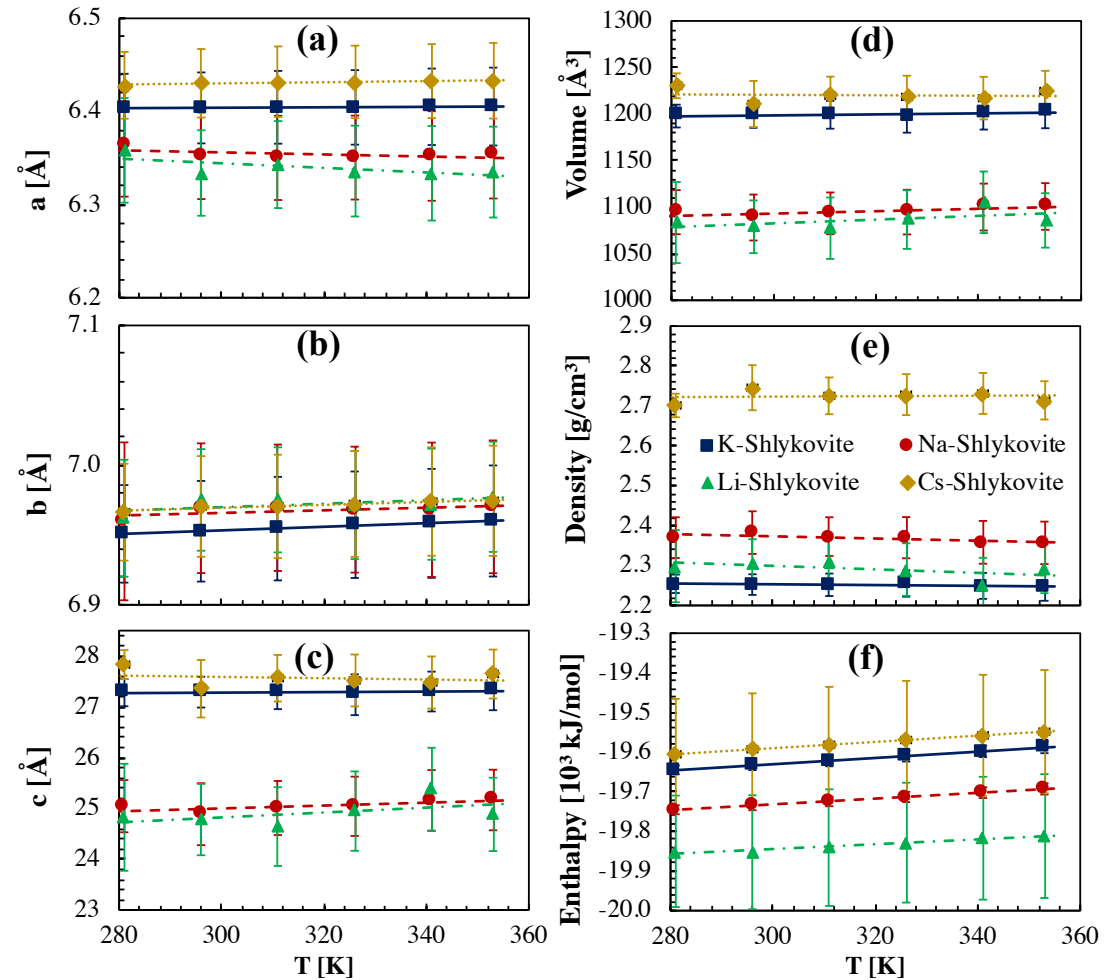

Figure 4: Temperature dependence of the (a)-(c) lattice parameters, (d) volume of the unit cell, (e) density and (f) molar enthalpy of Li-, Na-, K- and Cs-shlykovite under $1 \mathrm{~atm}$.

\subsubsection{Temperature dependence and thermal properties under undrained condi- tions}

Figure 4 shows the evolution of the lattice parameters of Li, Na-, K- and Cs-shlykovite obtained in $\mathrm{N} \sigma \mathrm{T}$ simulations as a function of the temperature, in a range that can be associated to most of the application of cement-based materials.

The coefficients of thermal expansion can be computed from the least square fitting of the results concerning cell vector in Fig. 4 using the $\alpha_{i j}=\left(\frac{\partial \epsilon_{i j}}{\partial T}\right)_{\sigma}$, where $\epsilon_{i j}$ is the strain tensor. For an orthogonal simulation box, the unit cell vector is identical to a Cartesian orthogonal frame; therefore, we may compute the anisotropic tensor of coefficients of thermal expansion directly from the vari- 
ation in the cell parameters. we used the definition of a "true" strain along a direction $i: \epsilon_{i}=\int d i / i=\operatorname{Ln}\left(i / i_{0}\right)$, where $i_{0}$ is the length at a reference temperature. For comparison, we also compute the isotropic coefficient of thermal expansion obtained from volume versus temperature fitting with the expression: $\alpha^{i s o}=\left(\frac{1}{V_{0}} \frac{\partial V}{\partial T}\right)_{\sigma}$, where $V_{0}$ is the volume at a reference temperature. In both cases, we adopt $296 \mathrm{~K}$ as the reference temperature. The results are reported in Table 2 and plotted in Fig. 5. The sequence of the coefficient of thermal expansion along $a$-direction follows $\mathrm{Li}<\mathrm{Na}<\mathrm{K}<\mathrm{Cs}$ (with thermal contraction for Li- and Na-shlykovite); along c-direction, follows the inverse order (with thermal contraction for Cs-shlykovite); and along $b$ - direction shows no clear effect of the specific charge balance ion. Anisotropic thermal contraction have been observed in layered crystal (e.g. [32, 33. The volumetric coefficient of thermal expansion $\left(\operatorname{Tr}(\alpha)\right.$ or $\left.\alpha^{i s o}\right)$ follows the $c$ leading order. K-Shlykovite exhibits a coefficient of thermal expansion similar to $\mathrm{C}-\mathrm{S}-\mathrm{H}\left(42 \times 10^{-6}\right.$ to $\left.45 \times 10^{-6} 1 / \mathrm{K}\right)$ and clinker minerals $\left(50 \times 10^{-6} 1 / \mathrm{K}\right)$, whereas Na-shlykovite exhibits a coefficient of thermal expansion closer to portlandite's $\left(70 \times 10^{-6}\right.$ to $\left.\left.99.1 \times 10^{-6} 1 / \mathrm{K}\right)\right)$ 34 .

The molar enthalpies (obtained in $\mathrm{N} \sigma \mathrm{T}$ simulations) of $\mathrm{Li}, \mathrm{Na}, \mathrm{K}$ - and Csshlykovite are plotted against the temperature in Fig. 4 (e) and follows Li < $\mathrm{Na}<\mathrm{K}<\mathrm{Cs}$. These energy values computed by MD informs on the cohesive energy of the solid [35]. Lattice enthalpy [36], which can be computed from experimental considerations, can be compared to the value obtained in MD simulation. The molar enthalpies at $298 \mathrm{~K}$, gathered in Table 2, were obtained from interpolation of the values in Fig. 4 (f). The heat capacity at constant stress $C_{P}$ is reported in Table 2 are computed from the least square fitting of the results in Fig. 4 (f). The results in $\mathrm{J} /($ mol.K) follows $\mathrm{Li}<\mathrm{Na}<\mathrm{K} \approx \mathrm{Cs}$ (Fig. 5).

\subsubsection{Elastic constants under undrained conditions}

180 A crystal with monoclinic symmetry has thirteen non-zero independent components in its elastic tensors. In the molecular simulation performed here, all 
Table 2: Coefficients of thermal expansion (component $\alpha_{i}$ along vector $i$, trace of anisotropic tensor $\operatorname{Tr}(\alpha) /$, and $\alpha^{\text {iso }}$ computed from volume derivatives), constant stress heat capacity $\left(C_{P}\right)$ and molar enthalpy $\left(H_{m, 298}\right)$.

\begin{tabular}{c|cccc}
\hline & Li-Shly. & Na-Shly. & K-Shly. & Cs-Shly \\
\hline$\alpha_{a}\left[10^{-6} 1 / \mathrm{K}\right]$ & -38.9 & -17.4 & 3.7 & 9.64 \\
$\alpha_{b}\left[10^{-6} 1 / \mathrm{K}\right]$ & 18.0 & 13.5 & 18.7 & 15.2 \\
$\alpha_{c}\left[10^{-6} 1 / \mathrm{K}\right]$ & 193.0 & 113.3 & 18.8 & -45.9 \\
$\operatorname{Tr}(\alpha) /\left[10^{-6} 1 / \mathrm{K}\right]$ & 172.1 & 109.3 & 41.2 & -21.2 \\
$\alpha^{i s o}\left[10^{-6} 1 / \mathrm{K}\right]$ & 185.9 & 117.1 & 45.5 & -19.7 \\
\hline$H_{m, 298}\left[10^{3} \mathrm{~kJ} / \mathrm{mol}\right]$ & -19.85 & -19.73 & -19.63 & -19.59 \\
\hline$C_{P}[\mathrm{~J} /(\mathrm{mol} . \mathrm{K})]$ & 608.5 & 726.4 & 792.3 & 788.9 \\
$C_{P}[\mathrm{~J} /(\mathrm{kg} . \mathrm{K})]$ & 1624 & 1860 & 1949 & 1576 \\
\hline
\end{tabular}

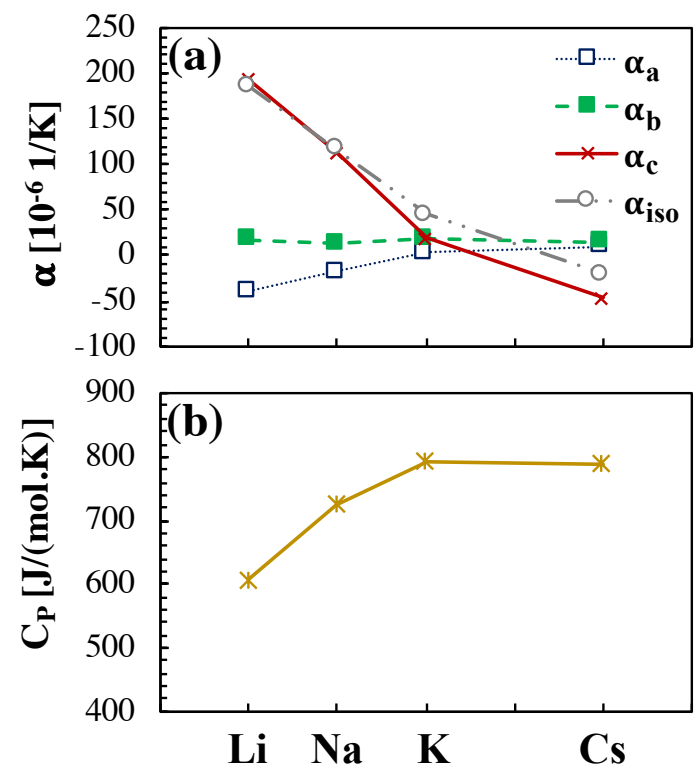

Figure 5: Dependence of the charge balance ion of the (a) coefficients of thermal expansion; (b) heat capacity at constant stress of Li-, Na-, K- and Cs-shlykovite. 
Table 3: Components of stiffness tensor $\mathrm{C}_{i j}[\mathrm{GPa}]$ in Voigt notation, elastic moduli (bulk $K$, shear $G$, Young's $E$ and indentation $M$ moduli) and Poisson ratio $\nu$ of Li-, Na-, K- and Csshlykovite. Systems at constant number of water molecules $n=3$ per $\mathrm{Ca}\left[\mathrm{Si}_{4} \mathrm{O}_{9}(\mathrm{OH})\right]$. Only the $\mathrm{C}_{i j}$ terms that are expected to be non-zero in a monoclinic crystal in the standard orientation (i.e diad axis parallel to [010]) are shown. The self-consistent estimation of the Young modulus $E^{S C}$ at two limit packing densities $\eta: \eta=0.64$ (subscript LD, for low density) for the random packing limit and $\eta=0.74$ (subscript HD, for high density) for fcc or hcp packing limit [37.

\begin{tabular}{ccccc}
\hline & Li-Shly. & Na-Shly. & K-Shly. & Cs-Shly \\
\hline $\mathrm{C}_{11}$ & 147.3 & 142.2 & 137.6 & 139.6 \\
$\mathrm{C}_{22}$ & 174.1 & 183.5 & 175.3 & 190.2 \\
$\mathrm{C}_{33}$ & 37.8 & 73.9 & 70.4 & 61.7 \\
$\mathrm{C}_{12}$ & 67.5 & 67.5 & 65.9 & 69.1 \\
$\mathrm{C}_{13}$ & 17.5 & 6.3 & 18.9 & 21.0 \\
$\mathrm{C}_{23}$ & 16.9 & 26.4 & 31.2 & 33.2 \\
$\mathrm{C}_{44}$ & 13.4 & 24.4 & 22.0 & 24.2 \\
$\mathrm{C}_{55}$ & 14.6 & 14.3 & 13.3 & 13.0 \\
$\mathrm{C}_{66}$ & 44.5 & 29.4 & 28.1 & 44.0 \\
$\mathrm{C}_{15}$ & 5.5 & 3.7 & 5.0 & 1.3 \\
$\mathrm{C}_{25}$ & -4.3 & -3.0 & -0.8 & -6.1 \\
$\mathrm{C}_{35}$ & -4.6 & 2.0 & -0.1 & 2.3 \\
$\mathrm{C}_{46}$ & -4.7 & -8.4 & -8.9 & -8.4 \\
\hline$K$ & 57.4 & 80.5 & 73.9 & 74.7 \\
$G$ & 26.3 & 29.8 & 28.3 & 34.4 \\
$E$ & 68.5 & 79.6 & 75.2 & 89.6 \\
$\nu$ & 0.30 & 0.34 & 0.33 & 0.30 \\
$M$ & 75.3 & 89.7 & 84.4 & 98.43 \\
\hline$C_{L}^{S C}(\eta=0.64)$ & 19.0 & 22.1 & 20.9 & 24.9 \\
$E_{H}^{S C}(\eta=0.74)$ & 32.8 & 38.1 & 36.0 & 42.8 \\
\hline & & & &
\end{tabular}

terms were computed from independent simulation involving each component of the stress tensor. A finite deformation of 0.002 was applied. Table 3 gathers the independent components of stiffness tensor $\mathrm{C}_{i j}$ of Li-, Na-, K- and Cs-shlykovite. For components that should be zero the observed differences in the simulation results did not exceed a few GPa.

The estimations of the bulk $K$ and shear $G$ moduli using Voigt-Reuss-Hill approach as well as Poisson ratio $\nu$, Young modulus $E$ and the indentation modulus $M$ for Li-, Na-, $\mathrm{K}$ - and Cs-shlykovite are also provided in Table 3 and plotted in Fig. 6. The Voigt-Reuss-Hill (VRH) approximation on the bulk $K$ and shear $G$ moduli are computed from the respective Voigt (subscript ${ }_{V}$ ) and Reuss (subscript ${ }_{R}$ ) bounds [38]. Assuming a macro-isotropic material, the Young $E$ modulus and the Poisson ratio $\nu$ can be obtained using: $E=$ 

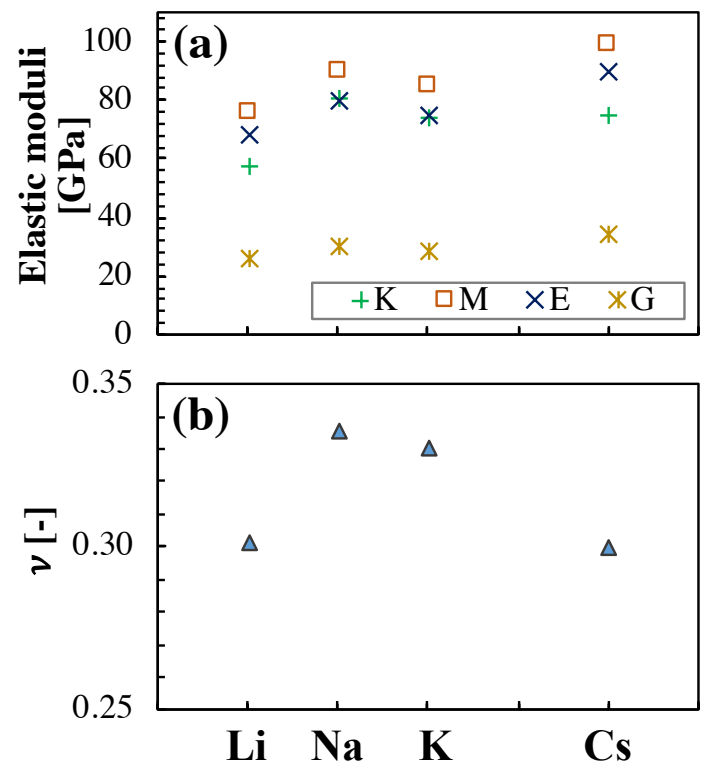

Figure 6: Dependence of the charge balance ion of the (a) elastic moduli (bulk $K$, shear $G$, Young's $E$ and indentation $M$ moduli); and (b) Poisson ratio $\nu$ of Li-, Na-, K- and Csshlykovite.

$9 K G /(3 K+G)$ and $\nu=(3 K-2 G) /(6 K+2 G)$ from which the indentation modulus $M=E /\left(1-\nu^{2}\right)$ can be computed.

The elastic moduli are plotted according to the charge balance cation in Fig. 6. The global tendency seems to increase the elastic moduli with the radius of the charge balance cation, but a local minimum is observed for K-shlykovite. The Poisson ratio exhibits a maximum value for Na-shlykovite.

The Young moduli obtained for Li-, Na- and K-shlykovite agree with the nano-indentation results provided by Zhang et al. [39]: $E=65 \pm 12.3 \mathrm{GPa}$. Micro-indentation results are expected to yield lower elastic constant due to disorder and additional porosity observed in the gel mesoscale (depicted in the sketch in Fig. 17. For example, Leemann et al. 40] report micro-indentation of ASR produts with $E$ in the range 9-11 GPa. Hu et al. report $E$ of rosettelike ASR product ranging from 13.7 to $42.7 \mathrm{GPa}$ [41. We test the hypothesis whether, akin to C-S-H gel, the variability observed in the experimental mea- 
sured elastic moduli of ASR gels can be explained by the packing of the gel particles. To do, so we adopt the self-consistent (SC) estimate for micro- and macro-isotropic heterogenous material constituted of equiaxed particles [42. The SC effective bulk $K^{S C}$ and shear $G^{S C}$ moduli are obtained solving the implicit equations [42]:

$$
\sum_{r=1}^{N} f_{r} \frac{K_{r}-K^{S C}}{K_{r}+4 / 3 G^{S C}}=0 ; \quad \sum_{r=1}^{N} f_{r} \frac{G_{r}-G^{S C}}{G_{r}+H^{S C}}=0
$$

where $f_{r}, K_{r}$ and $G_{r}$ are the volume fraction, bulk modulus and shear modulus of the phase $r$, and $H^{S C}=G^{S C}\left(3 K^{S C} / 2+4 G^{S C} / 3\right) /\left(K^{S C}+2 G^{S C}\right)$. The $\mathrm{SC}$ estimation of the Young modulus $E^{S C}=9 K^{S C} G^{S C} /\left(3 K^{S C}+G^{S C}\right)$ can be then computed using $K^{S C}$ and $G^{S C}$. For C-S-H, the two limit packing densities $\eta, \eta=0.64$ (called usually low density (LD)) for the random packing limit and $\eta=0.74$ (called usually high density (HD)) for fcc or hcp packing have been associated with the average packing densities [37. We report in Table 3 the SC estimate of the Young modulus $E^{S C}$ for both packing densities. The estimates are in agreement with the variability observed in the experimental investigations of the elastic properties of ASR products [40, 41, 39]. These results corroborate the hypothesis regarding the nanogranular nature of ASR gels, whose mesotexture could be explained by limit grain packing analogously to C-S-H gels 37.

To further investigate the influence of charge balance ions in the mechanical response, we performed a simulation of isotropic compression followed by decompression of Li-, Na-, K- and Cs-shlykovite, as shown in Fig. 7. The results are compared to the experimental data of Geng et al. 43. on synthesized ${ }_{230}$ K-shlykovite, and Moon et al. 44] on ASR gels. The slopes for all the cases are in agreement with the experimental results. Note that at the gel scale (experimental data), due to disorder, the density is expected to be lower than that of the nanocrystalline phase (MD simulations). The curves of density plotted against the pressure for $\mathrm{Li}-$, Na- and K-shlykovite are closer and the response is reversible. Geng et al. 43] also found the change of K-shlykovite struc- 


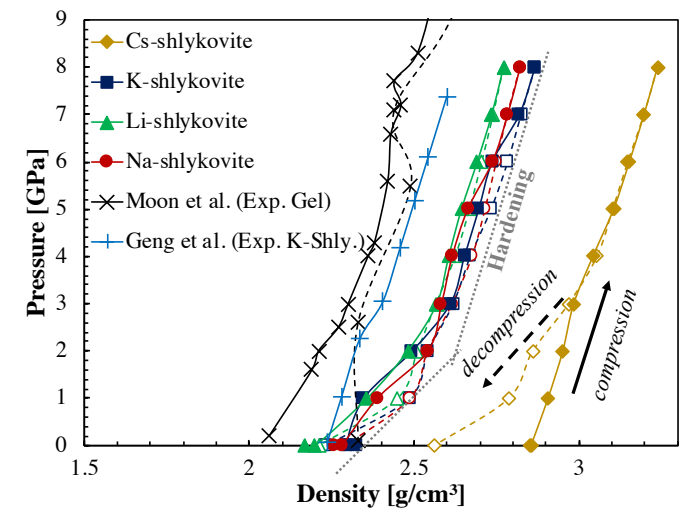

Figure 7: Isotropic compression and decompression of Li-, Na-, K- and Cs-shlykovite: comparison against the experimental data of Moon et al. 44] on ASR gels, and Geng et al [43] on $\mathrm{K}$-shlykovite. Systems at constant number of water molecules $n=3$ per $\mathrm{Ca}\left[\mathrm{Si}_{4} \mathrm{O}_{9}(\mathrm{OH})\right]$. Solid lines denote compression and dashed lines denote decompression.

ture is reversible under the same compression and decompression in the same pressure range. For these curves, hardening is observed for pressures exceeding approximately $2 \mathrm{GPa}$. The curve associated with Cs-shlykovite exhibits marked irreversibility under decompression. Simulations with pressure exceeding $8 \mathrm{GPa}$ showed, though, irreversibilities for all cases (the results are not considered here because such large pressures are not relevant for concrete industrial applications).

\subsubsection{Nanoscale origin of the thermomechanical properties}

To understand the origin of the differences in the thermomechanical properties presented in the previous section we look at the changes in water structure and hydrogen bond network induced by the presence of the different charge balance cations.

The RDFs of each charge balance cation and water oxygen are shown in Fig. 8(a) for Li-, Na-, K- and Cs-shlykovite. The first hydration shells are clearly identified in these RDFs (the corresponding plateaus are shown in the inset). The hydration numbers $n_{1 W}$ (i.e. the number of water molecules coordinated by the cations) associated with the first shell are gathered in Table 4 The 
Table 4: Hydration number $n_{1 W}$, position (peak) of the first and second hydration $\left(d_{i o n-W}^{1 W}\right.$ and $d_{i o n-W}^{2 W}$, respectively) shells of ions, total number of hydrogen bonds $H B$ and decomposition in terms of $\mathrm{H}$-bonds between water oxygen $\mathrm{HB}^{W W}$, layer $\mathrm{OH}$ groups $\mathrm{HB}^{L L}$ and water oxygen and layer $\mathrm{OH}$ groups $\mathrm{HB}^{W L}$.

\begin{tabular}{ccccc}
\hline & Li- & $\mathrm{Na}$ & $\mathrm{K}$ & $\mathrm{Cs}$ \\
\hline$n_{1 W}$ & 2.25 & 2.48 & 2.60 & 2.47 \\
$d_{i o n}^{1 W}\left[\begin{array}{l}\text { W } \\
d_{i o n}^{2} W-W\end{array}\right.$ & 2.03 & 2.32 & 2.78 & 3.07 \\
\hline$H B W W$ & 3.83 & $3.83(4.43)$ & 4.48 & 4.43 \\
$H B W L$ & $0.61 \pm 0.18$ & $0.84 \pm 0.10$ & $0.94 \pm 0.09$ & $0.95 \pm 0.08$ \\
$H B L$ & $0.20 \pm 0.10$ & $0.70 \pm 0.14$ & $0.84 \pm 0.08$ & $0.88 \pm 0.05$ \\
$H B$ & 0 & 0 & 0 & 0 \\
\hline$B_{B} W$ & $0.81 \pm 0.21$ & $1.55 \pm 0.18$ & $1.79 \pm 0.12$ & $1.84 \pm 0.10$ \\
\hline
\end{tabular}

second shells are less pronounced in all cases, with K-shlykovite exhibiting an intermediary peak at approximately $3.7 \AA$. The RDF of oxygen of water confined in shlykovite is compared to the that of bulk SPC/E water in Fig. 8(b). The presence of well-defined peaks indicates the ordered aspect of water molecules confined in shlykovite. The position of the first peak is similar to that of bulk water, except for Li-shlykovite.

The density profiles along $c$ direction are shown in Fig. 8 (c). We adopt the scheme depicted in Fig. 1(a) to define the solid layers (with intralayer water) and the interlayer pore. The position of charge balance cation remains the same in all cases: the cation forms inner complexes within silicate channel (inbetween the Si atoms in the main layer and the Si atoms projected outwards the main layer) as calcium counterions in tobermorite [25. The intralayer water exhibits a similar structure with two oxygen well-identified layers, irrespective of the charge balance cation. On the other hand, the interlayer water structure is strongly affected by the counterion type. Water oxygen is ordered in the interlayer so that four peaks are observed in Na-shlykovite, three peaks in Lishlykovite, and two peaks in K- and Cs-shlykovite.

We analyze the number of hydrogen bonds according to the charge balance cation in Fig. 9. We adopt the following criteria to define an H-bonds [45, 46]: donor-acceptor oxygen distance of $d_{O . . O}<3.5 \AA$ and angle between O-H and $\mathrm{O} \ldots \mathrm{O}$ vectors $\theta_{H B}<30^{\circ}$. We separate the contributions to the total H-bonds 

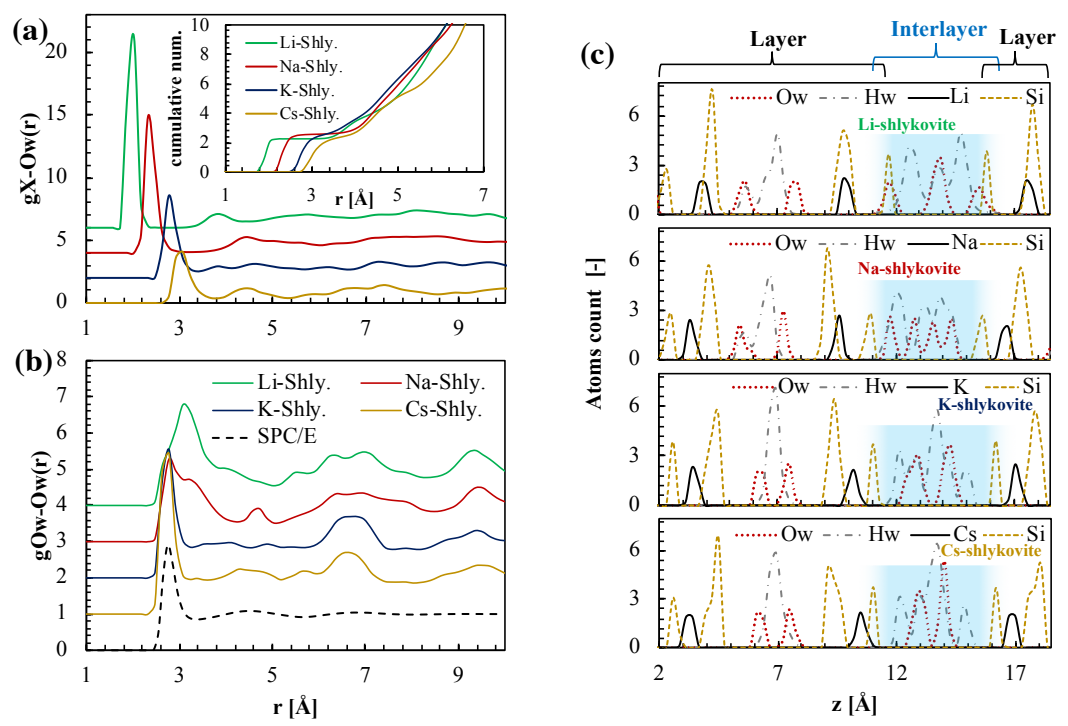

Figure 8: RDF of (a) charge balance cation $(X=\mathrm{Li}, \mathrm{Na}, \mathrm{K}, \mathrm{Cs})$ and water oxygen $g_{X-O_{w}}(r)$ and (b) water oxygen $g_{O_{w}-O_{w}}(r)$ in Li-, Na-, K- and Cs-shlykovite. The inset in (a) shows the cumulative number of the water oxygens coordinates by the charge balance cations. The $\mathrm{RDF}$ of water oxygens in bulk SPC/E water is shown in (b) for comparison. (c) Z-profiles of water oxygen and hydrogen, silicon and counterions. 
$H B$ according to the $\mathrm{H}$-bonds between water oxygen $\mathrm{HB}^{W W}$, layer $\mathrm{OH}$ groups $\mathrm{HB}^{L L}$ and water oxygen and layer $\mathrm{OH}$ groups $\mathrm{HB}^{W L}$ :

$$
H B=H B^{W W}+H B^{L L}+H B^{W L}
$$

The values are also listed in Tab. 4. The $H B^{L L}$ is zero for all cases considered. The number of $\mathrm{HB}^{W W}$ and $\mathrm{HB}^{W L}$ (and therefore $H B$ ) follows $\mathrm{Cs}>\mathrm{K}>\mathrm{Na}>$ Li. In all cases, the total H-bonds remain lower than the value of bulk SPC/E water reported in the literature of 3.2 to $3.4 \mathrm{H}$-bonds per water molecule [47. The individual contributions of $\mathrm{HB}^{W W}$ and $\mathrm{HB}^{W L}$ follow the same trends.

To unveil the role of hydrogen bonding in the thermo-mechanical properties, we plot the normalized elastic moduli, coefficient of thermal expansion and heat capacity in Figures 9 (b), (c) and (d), respectively. General trends are observed with (i) the elastic moduli (except for K-shlykovite) and heat capacity increasing, and (ii) the coefficient of thermal-expansion decreasing (except for $\alpha_{b}$ ) with the number of H-bonds. This observation shows one of the main mechanisms through which charge balance ions change the thermo-mechanics of shlykovite is though the modification of H-bond networks.

\section{Conclusion}

Molecular modeling of crystalline ASR products was proposed based on shlykovite structure with Li, Na-, K- or Cs- substitutions. We show the critical role of charge balance cation on the thermo-mechanical properties of phyllosilicates, with clear trends identified for the elastic moduli, heat capacity, and coefficient of thermal expansion as a function of the ion size. Since the experimental characterization of the thermo-mechanical properties of ASR products is challenging, the results provided in this work are valuable information for bottom-up modeling of ASR damage and can be used to improve the precision and increase confidence in multiscale modeling. We conclude:

- Molecular modeling of shlykovite structure with ClayFF is transferable to the study of thermo-mechanical properties of ASR products. The molecular 

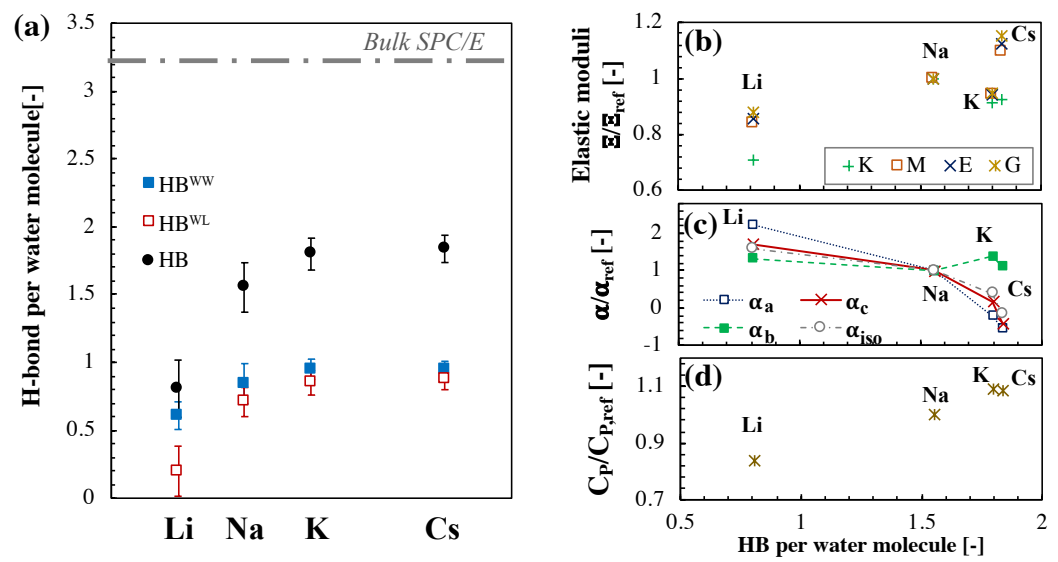

Figure 9: (a) Total H-bonds $H B$ decomposed in the contributions of H-bonds between water oxygen $\mathrm{HB}^{W W}$, and water oxygen and layer $\mathrm{OH}$ groups $\mathrm{HB}^{W L}$ for $\mathrm{Li}-$, Na-, $\mathrm{K}-$, and Csshlykovite. Normalized thermomechanical properties as a function of $H B$ : (b) elastic moduli (bulk $K$, shear $G$ and Young $E$ moduli), (c) components of anisotropic thermal expansion tensor and (d) constant stress heat capacity. The properties were normalized with respect to the properties of Na-shlykovite.

modeling is in agreement with experimental evidence regarding the structure, lattice parameters, and elastic properties of ASR products found in concrete.

- The difference of elastic properties of ASR products at the molecular and mesoscale suggests a nanogranular mesotexture of ASR products. The self-consistent estimates, from mean-field micromechanics theory, using the packing limits of monodisperse spheres explains the variability observed in the elastic modulus obtained from nano- and micro-indentation experiments on ASR products.

- The charge balancing ion affects the thermo-mechanical properties by increasing the number of hydrogen bonds in the phyllosilicate. The augmentation of $\mathrm{H}$-bonds in the sequence $\mathrm{Cs}>\mathrm{K}>\mathrm{Na}>\mathrm{Li}$ translates in an augmentation of the elastic constants and heat capacity, and on the decrease of the volumetric thermal expansion coefficient. The link be- 
tween H-bonds number and thermomechanical properties shows that one of the main mechanisms through which charge balance ions change the thermo-mechanical response of layered adsorbing materials is through the modification of H-bond networks. This observation can be used to understand the physical origins of properties in other phyllosilicates in which various charge balance ion can exchange with the interlayer fluid, such as clays [48] and C-S-H. Furthermore, these results show the importance of accounting for specific ion effects in the bottom-up modeling of phyllosilicates properties as well as in investigations dealing with disordered silicate gel structures.

\section{References}

[1] E. S. Boek, P. V. Coveney, N. T. Skipper, Molecular Modeling of Clay Hydration: A Study of Hysteresis Loops in the Swelling Curves of Sodium Montmorillonites, Langmuir 11 (12) (1995) 4629-4631 (Dec. 1995).

[2] B. Carrier, M. Vandamme, R. J.-M. Pellenq, H. Van Damme, Elastic Properties of Swelling Clay Particles at Finite Temperature upon Hydration, The Journal of Physical Chemistry C 118 (17) (2014) 8933-8943 (May 2014).

[3] T. J. Tambach, P. G. Bolhuis, E. J. M. Hensen, B. Smit, Hysteresis in Clay Swelling Induced by Hydrogen Bonding: Accurate Prediction of Swelling States, Langmuir 22 (3) (2006) 1223-1234 (Jan. 2006).

[4] R. J. Flatt, N. Roussel, C. R. Cheeseman, Concrete: An eco material that needs to be improved, Journal of the European Ceramic Society 32 (11) (2012) 2787-2798 (Aug. 2012).

[5] L. S. Dent Glasser, N. Kataoka, The chemistry of 'alkali-aggregate' reaction, Cement and Concrete Research 11 (1) (1981) 1-9 (Jan. 1981).

[6] F. Rajabipour, E. Giannini, C. Dunant, J. H. Ideker, M. D. A. Thomas, Alkali-silica reaction: Current understanding of the reaction mechanisms 
and the knowledge gaps, Cement and Concrete Research 76 (2015) 130-146 (Oct. 2015).

[12] Z. Shi, G. Geng, A. Leemann, B. Lothenbach, Synthesis, characterization, and water uptake property of alkali-silica reaction products, Cement and Concrete Research 121 (2019) 58-71 (Jul. 2019).

[13] R. J. Prado, F. Tiecher, N. P. Hasparyk, D. C. C. D. Molin, Structural char-

[7] A. Leemann, T. Katayama, I. Fernandes, M. A. T. M. Broekmans, Types of alkali-aggregate reactions and the products formed, Proceedings of the Institution of Civil Engineers - Construction Materials 169 (3) (2016) 128135 (Feb. 2016).

[8] S. Multon, F. Toutlemonde, Effect of applied stresses on alkali-silica reaction-induced expansions, Cement and Concrete Research 36 (5) (2006) 912-920 (May 2006).

[9] S. Multon, F. Toutlemonde, Effect of moisture conditions and transfers on alkali silica reaction damaged structures, Cement and Concrete Research 40 (6) (2010) 924-934 (Jun. 2010).

[10] C. J. Benmore, P. J. M. Monteiro, The structure of alkali silicate gel by total scattering methods, Cement and Concrete Research 40 (6) (2010) 892-897 (Jun. 2010).

[11] R. J. Kirkpatrick, Experimental and molecular dynamics modeling studies of interlayer swelling: water incorporation in kanemite and ASR gel, Materials and Structures 38 (278) (2005) 449-458 (Feb. 2005). acterization of alkali-silica reaction gel: An x-ray absorption fine structure study, Cement and Concrete Research 123 (2019) 105774 (Sep. 2019).

[14] N. V. Zubkova, Y. E. Filinchuk, I. V. Pekov, D. Y. Pushcharovsky, E. R. Gobechiya, Crystal structures of shlykovite and cryptophyllite: comparative crystal chemistry of phyllosilicate minerals of the mountainite family, European Journal of Mineralogy 22 (4) (2010) 547-555 (Aug. 2010). 
[15] A. Vollpracht, B. Lothenbach, R. Snellings, J. Haufe, The pore solution of blended cements: a review, Materials and Structures 49 (8) (2016) 33413367 (Aug. 2016).

[16] T. Honorio, F. Benboudjema, T. Bore, M. Ferhat, E. Vourc'h, The pore solution of cement-based materials: structure and dynamics of water and ions from molecular simulations, Physical Chemistry Chemical Physics 21 (2019) 11111-11121 (2019).

[17] A. Leemann, L. Lörtscher, L. Bernard, G. Le Saout, B. Lothenbach, R. M. Espinosa-Marzal, Mitigation of ASR by the use of LiNO3Characterization of the reaction products, Cement and Concrete Research 59 (2014) 73-86 (May 2014).

[18] A. Leemann, B. Münch, The addition of caesium to concrete with alkalisilica reaction: Implications on product identification and recognition of the reaction sequence, Cement and Concrete Research 120 (2019) 27-35 (Jun. 2019). doi:10.1016/j.cemconres.2019.03.016.

[19] T. Honorio, O. M. Chemgne Tamouya, Z. Shi, A. Bourdot, Intermolecular interactions of nanocrystalline alkali-silica reaction products under sorption, Cement and Concrete Research 136 (Oct. 2020). doi:10.1016/j. cemconres.2020.106155.

[20] R. T. Cygan, J.-J. Liang, A. G. Kalinichev, Molecular Models of Hydroxide, Oxyhydroxide, and Clay Phases and the Development of a General Force Field, The Journal of Physical Chemistry B 108 (4) (2004) 1255-1266 (Jan. 2004).

[21] H. J. C. Berendsen, J. R. Grigera, T. P. Straatsma, The missing term in effective pair potentials, The Journal of Physical Chemistry 91 (24) (1987) 6269-6271 (Nov. 1987). doi:10.1021/j100308a038.

[22] D. E. Smith, Molecular Computer Simulations of the Swelling Properties 
and Interlayer Structure of Cesium Montmorillonite, Langmuir 14 (20) (1998) 5959-5967 (Sep. 1998).

[30] T. Honorio, L. Brochard, M. Vandamme, Hydration Phase Diagram of Clay Particles from Molecular Simulations, Langmuir 33 (44) (2017) 1276612776 (Nov. 2017). 
[31] Z. P. Bazant, A. B. Hauggaard, S. Baweja, F.-J. Ulm, Microprestresssolidification theory for concrete creep. I: Aging and drying effects, Journal of Engineering Mechanics 123 (11) (1997) 1188-1194 (1997).

[32] T. Honorio, T. Lemaire, D. D. Tommaso, S. Naili, Molecular modelling of the heat capacity and anisotropic thermal expansion of nanoporous hydroxyapatite, Materialia (2019) 100251 (Feb. 2019).

[33] I. Lifshitz, Thermal properties of chain and layered structures at low temperatures, Zh. Eksp. Teor. Fiz 22 (4) (1952) 475-486 (1952).

[34] T. Honorio, B. Bary, F. Benboudjema, Thermal properties of cement-based materials: Multiscale estimations at early-age, Cement and Concrete Composites 87 (2018) 205-219 (Mar. 2018).

[35] F. J. A. L. Cruz, J. N. Canongia Lopes, J. C. G. Calado, M. E. Minas da Piedade, A Molecular Dynamics Study of the Thermodynamic Properties of Calcium Apatites. 1. Hexagonal Phases, The Journal of Physical Chemistry B 109 (51) (2005) 24473-24479 (Dec. 2005).

[36] H. D. B. Jenkins, Thermodynamics of the Relationship between Lattice Energy and Lattice Enthalpy, Journal of Chemical Education 82 (6) (2005) 950 (Jun. 2005).

[37] G. Constantinides, F.-J. Ulm, The nanogranular nature of C-S-H, Journal of the Mechanics and Physics of Solids 55 (1) (2007) 64-90 (Jan. 2007).

[38] R. Hill, The Elastic Behaviour of a Crystalline Aggregate, Proceedings of the Physical Society. Section A 65 (5) (1952) 349 (1952).

[39] C. Zhang, L. Sorelli, B. Fournier, J. Duchesne, J. Bastien, Z. Chen, Stressrelaxation of crystalline alkali-silica reaction products: Characterization by micro- and nanoindentation and simplified modeling, Construction and Building Materials 148 (2017) 455-464 (Sep. 2017). 
[40] A. Leemann, P. Lura, E-modulus of the alkali-silica-reaction product determined by micro-indentation, Construction and Building Materials 44 (2013) 221-227 (Jul. 2013).

[41] C. Hu, B. P. Gautam, D. K. Panesar, Nano-mechanical properties of alkalisilica reaction (ASR) products in concrete measured by nano-indentation, Construction and Building Materials 158 (2018) 75-83 (Jan. 2018).

[42] R. Hill, A self-consistent mechanics of composite materials, Journal of the Mechanics and Physics of Solids 13 (4) (1965) 213-222 (Aug. 1965).

[43] G. Geng, Z. Shi, A. Leemann, K. Glazyrin, A. Kleppe, D. Daisenberger, S. Churakov, B. Lothenbach, E. Wieland, R. Dähn, Mechanical behavtal Engineering and Materials 76 (4) (2020) 674-682 (Aug. 2020). doi: 10.1107/S205252062000846X

[44] J. Moon, S. Speziale, C. Meral, B. Kalkan, S. M. Clark, P. J. M. Monteiro, Determination of the elastic properties of amorphous materials: Case study of alkali-silica reaction gel, Cement and Concrete Research 54 (2013) 55-60 (Dec. 2013). doi:10.1016/j.cemconres.2013.08.012.

[45] A. Luzar, D. Chandler, Structure and hydrogen bond dynamics of waterdimethyl sulfoxide mixtures by computer simulations, The Journal of Chemical Physics 98 (10) (1993) 8160-8173 (May 1993).

[46] A. Luzar, D. Chandler, Hydrogen-bond kinetics in liquid water, Nature 379 (6560) (1996) 55-57 (Jan. 1996).

[47] Y. Marcus, Effect of Ions on the Structure of Water: Structure Making and Breaking, Chemical Reviews 109 (3) (2009) 1346-1370 (Mar. 2009).

${ }_{475}^{6}$ [48] H. D. Whitley, D. E. Smith, Free energy, energy, and entropy of swelling in Cs-, Na-, and Sr-montmorillonite clays, The Journal of Chemical Physics 120 (11) (2004) 5387-5395 (Mar. 2004). 